\title{
A PRODUÇÃO DO CONHECIMENTO EM EDUCAÇÃO NUM CONTEXTO DE ESTADO DE EXCEÇÃO E INTERDIÇÃO DOS DIREITOS
}

\author{
G. FRIGOTTO \\ Programa Pós-Graduação em Políticas Públicas e Formação Humana, Universidade do Estado do Rio de Janeiro \\ gfrigotto@globo.com \\ Submetido 22/02/2018 - Aceito 13/05/2018 \\ DOI: $10.15628 /$ holos.2018.6977
}

\section{RESUMO}

Este artigo discute os seguintes pontos: Quais as circunstâncias em que nos encontramos e somos instados a modificá-las para que se desenhe um futuro previsível? O que está subjacente e quais os elementos novos do golpe de Estado de agosto de 2016? Ou de onde viemos, o que nos trouxe até aqui e como interpretar o presente? Finalmente, quais os desafios e tarefas que nos são demandados para alterar as circunstâncias no plano do conhecimento e da restauração do estado de direito e a frágil ordem democrática?

PALAVRAS-CHAVE: Educação, Golpe de estado, Brasil, 2016.

\section{THE PRODUCTION OF KNOWLEDGE IN EDUCATION IN A CONTEXT OF A STATE OF EXCEPTION AND INTEREST OF RIGHTS}

\begin{abstract}
This article discusses the following points: What are the circumstances in which we find ourselves and are we urged to modify them in order to draw a predictable future? What underlies and what new elements of the August 2016 Institutional Coup? Or where did we come
\end{abstract}

from, what brought us here and how to interpret the present? Finally, what are the challenges and tasks that are required of us to change circumstances in terms of knowledge and the restoration of the rule of law and the fragile democratic order?

KEYWORDS: Education, Institutional Coup, Brazil, 2016. 


\section{INTRODUÇÃO}

O tema de abertura do IV Colóquio Nacional e do I Internacional - Da circunstância da educação à transformação das circunstâncias - e o tema de encerramento - A produção do conhecimento em educação num contexto de estado de exceção e interdição dos direitos certamente buscam situar os enormes desafios que nos interpelam no plano do conhecimento e da prática política, no atual momento da sociedade brasileira.

Em diferentes passagens, Marx nos coloca a relação entre as circunstâncias dadas sob o capitalismo e a necessidade de sua modificação na produção do ser social. Já em a Sagrada Família sublinhou:

Se o homem é formado pelas circunstâncias, será necessário formar as circunstâncias humanamente. Se o homem é social por natureza, desenvolverá sua verdadeira natureza no seio da sociedade e somente ali, razão pela qual devemos medir o poder de sua natureza, não através do poder do indivíduo concreto, mas sim através do poder da sociedade [grifos meus]. (MARX, 2003, p. 163)

Isto significa que não há um mundo humano fora da história e que não nascemos humanos, mas nos tornamos humanos em sociedade. No mesmo texto, Marx desmistifica algo central presente em nossa sociedade, a violência. Mostra-nos que a violência e os crimes têm que ser entendidos como uma produção social, e não individual.

\footnotetext{
Se o homem não goza de liberdade em sentido materialista, quer dizer, se é livre não pela força negativa de poder evitar isso e aquilo, mas pelo poder positivo de fazer valer sua verdadeira individualidade, os crimes não deverão ser castigados no indivíduo, mas [devem-se] sim destruir as raízes antissociais do crime e dar a todos a margem social necessária para exteriorizar de um modo essencial sua vida [grifos meus]. (Ibid.p. 163)
}

$\mathrm{Na}$ brevidade deste texto, de forma muito esquemática, buscarei destacar os seguintes pontos: Quais as circunstâncias em que nos encontramos e somos instados a modificá-las para que se desenhe um futuro previsível? O que está subjacente e quais os elementos novos do golpe de Estado de agosto de 2016? Ou de onde viemos, o que nos trouxe até aqui e como interpretar o presente? Finalmente, quais os desafios e tarefas que nos são demandados para alterar as circunstâncias no plano do conhecimento e da restauração do estado de direito e a frágil ordem democrática? 


\section{Quais as circunstâncias em que nos encontramos e somos instados a modificá-las}

As circunstâncias dadas, e das quais devemos partir, circunscrevem-se no contexto de um golpe jurídico-parlamentar-midiático que suspendeu o estado de direito, conformando um estado de exceção com traços de estado policial. Um golpe que reitera as ditaduras, e seguidos golpes institucionais na sociedade brasileira, mas que engendra elementos novos de caráter econômico-social, político e educacional, profundamente regressivo, e que atinge duramente e sem precedentes os direitos elementares da classe trabalhadora.

Com efeito, a Emenda Constitucional no 241, que congelou por 20 anos o investimento na esfera pública, significa a interdição de investimentos na manutenção dos todos os direitos universais. Essa violência completa-se pelas contrarreformas da Previdência, em curso, e a reforma trabalhista, já aprovada. Esta tríade de reformas, em nome da austeridade - leia-se salvaguardar os lucros do capital em particular o financeiro - , expressa a síntese macabra de despossessão e exploração extrema da classe trabalhadora e a interdição do futuro para seus filhos e netos.

A contrarreforma do Ensino Médio, tema geral do I Colóquio Internacional, efetivada por expediente autoritário de Medida Provisória, expressa uma das regressões no Ensino Médio mais abrangentes entre todas as contrarreformas realizadas em momentos de ditaduras ou golpes institucionais.

Tudo isso ocorre por diferentes aspectos, entre eles por representar a real contrarreforma do Ensino Médio, planejada pelo bloco de poder que governou o Brasil na década de 1990, ao longo dos oito anos sob a presidência de Fernando Henrique Cardoso e o mandato do ministro da Educação Paulo Renato de Souza, mas que a resistência ativa não permitiu. Os intelectuais que atuaram naquele período no MEC, ou como assessores e consultores, são os autores e os condutores desta contrarreforma. Uma contrarreforma que se ajustava à adoção da doutrina neoliberal e ao projeto de venda do patrimônio público, mediante as privatizações do patrimônio público e o aprofundamento do projeto de capitalismo dependente.

A regressão é mais profunda porque, ao longo das últimas duas décadas, a classe dominante brasileira, em suas frações ou "facções" centro-direita e extrema direita, ganhou organicidade para o objetivo histórico que lhe é comum: defender os privilégios de uma minoria associada aos centros hegemônicos do capital e solidificar o projeto mercantil de Educação. É símbolo dessa unidade mais ampla a criação, em 2004, do Movimento Escola sem Partido e, no 
ano seguinte, do Movimento Todos pela Educação, capitaneado por 14 grandes grupos industriais e financeiros, aos quais se juntaram 18 institutos ou organizações privadas. Embora sejam dois movimentos que se correlacionam, o Movimento Todos pela Educação transformouse em um grupo dirigente no interior do aparelho do Estado, disputando a direção do projeto de Educação no conteúdo, na forma e no método.

O aspecto mais regressivo dá-se no plano da concepção do conhecimento, atualmente protagonizado pelos intelectuais do partido ideológico do Movimento Escola sem Partido. Aquilo que era subjacente na gestão do ministro Paulo Renato de Souza, no desenrolar do golpe de estado, é explicitado pela tese da neutralidade na produção do conhecimento e da neutralidade do professor no processo de sua socialização. Neutralidade que se postula ser controlada por uma lei que criminaliza os docentes e incita a delação por colegas, alunos ou pais aos que supostamente transgridem a neutralidade. Uma delação que é estimulada com traços de ódio, vendo nos docentes inimigos, vigias ou estupradores de inocentes pela moral. Neste momento, o fundamentalismo de extrema direita se une ao fundamentalismo religioso em expansão em nosso país. Aqui, reside a esfinge e o ovo de serpente.

A contrarreforma tem como foco barrar as concepções de educação omnilateral, formação politécnica ou tecnológica, escola unitária e a proposta, como a denominamos, travessa contraditória do Ensino Médio integrado. Com base em Gramsci, tratam de impedir as bases de conhecimento que permitem aos jovens compreender como funciona a sociedade humana (societas hominum) e a sociedade das coisas (societas rerum). Uma dupla interdição ao conhecimento que faculta aos filhos e filhas da classe trabalhadora à cidadania política e econômica, mesmo que nos termos restritos da democracia burguesa.

A cidadania política, que pressupõe os conhecimentos básicos para a leitura autônoma das relações sociais, elemento crucial numa sociedade que tem na mídia empresarial uma máquina de alienação em nome dos interesses do capital, e a cidadania econômica, que pressupõe a aquisição do conhecimento politécnico e/ou tecnológico. Ou seja, os fundamentos científicos que estão na base de todos os processos produtivos, dentro dos atuais, o padrão técnico.

Uma interdição que impede que a maioria dos jovens da classe trabalhadora tenha um Ensino Médio de qualidade, compatível com as exigências necessárias ao processo produtivo sob o atual padrão técnico. Condena-os, portanto. Além disso, obstrui o acesso desses jovens à universidade, especialmente a carreiras de maior valor social e econômico. A negação desta 
dupla cidadania é, pois, coerente e funcional com o projeto histórico de capitalismo dependente da classe burguesa brasileira. Por isto, pode-se afirmar que a histórica persistência da negação da educação básica de efetiva qualidade social aos filhos da classe trabalhadora não é falta de recursos, mas um projeto consciente da burguesia brasileira.

\section{O que está subjacente e quais os elementos novos do atual golpe de Estado ${ }^{1}$ ?}

Dentro da concepção do materialismo histórico, aprendemos que o tempo presente somente ganha compreensão pelas conexões, mediações, determinações de médio ou longo prazos que o constituem. Da mesma forma, aprendemos que não podemos confundir o fenômeno com o real. Cabe-nos, então, o esforço de buscar o que está subjacente à reiterada estratégia de ditaduras e golpes de Estado em nossa sociedade e o que de novo e destrutivo, humana e socialmente, tem o atual golpe de Estado.

O pensamento social crítico de intelectuais brasileiros nos mostra que em todas as circunstâncias de nossa história se abriu a possibilidade de efetivar mudanças estruturais, mas que a classe dominante brasileira resistiu ou deflagrou ditaduras ou golpes institucionais de diferentes alcances. Alfredo Bosi, Caio Pardo Junior, Florestan Fernandes e Francisco de Oliveira nos permitem delinear o traço permanente que une passado e presente e define o DNA golpista da classe dominante brasileira sempre que ela vê seus interesses ameaçados. .

Para Bosi, "o que atuou eficazmente em todo o período de construção do Brasil como Estado autônomo foi um ideário de fundo conservador; no caso, um complexo de normas jurídico-políticas capazes de garantir a propriedade fundiária e escrava até seu limite possível" (BOSI, 2010, p. 195). A escravidão durou quase quatro séculos e, mesmo juridicamente abolida em 1888, permanece nas relações sociais, de modo que - no caso de negros, pardos e índios até hoje, à desigualdade de classe soma-se o preconceito "racial" ou étnico.

Em sequência, a forma de relações sociais de produção capitalistas estrutura-se ao longo do século XX tardiamente, e, na perspectiva de Caio Prado Junior (1966), plasmadas por uma burguesia que nunca se preocupou em desenvolver ciência e tecnologia próprias, mas pautou-se pela cópia dos centros hegemônicos do capital. Como tal, não se interessou em desenvolver um mercado interno forte e sustentável, mas sempre preferiu depender do endividamento mediante

\footnotetext{
${ }^{1}$ As ideias aqui expressas resultam de análises pessoais e coletivas, em parte publicadas em textos recentes de minha autoria ou em colaboração com Maria Ciavatta, Marise Ramos e Vânia Motta. O objetivo de aspectos que se reiteram é a natureza do público a que se dirigem dominantemente.
} 
empréstimos externos, atualmente endividamento interno. Sustentar este modelo de sociedade e manter seus privilégios implicou e implica manter uma assimetria descomunal entre os ganhos do capital e o salário dos trabalhadores.

Estes traços de fundação de nossa especificidade histórica se consolidam e se reiteram ao longo do século $\mathrm{XX}$, mediante um projeto societário definido por Florestan Fernandes (1973-74) como de capitalismo dependente e de desenvolvimento desigual e combinado. Uma classe dominante que, diferente das burguesias dos países dos centros hegemônicos do capital, estabeleceu que nações autônomas e soberanas sempre buscaram associar-se de forma subordinada a estes centros hegemônicos, conformando uma sociedade com uma minoria e concentrando propriedade e riqueza à custa da manutenção da maioria na pobreza, em grande parte, na miséria. Francisco de Oliveira (2003) sintetiza com a imagem do ornitorrinco e a traduz, em termos sociais, como um mostrengo de sociedade na qual a classe dominante produz a miséria e se alimenta dela.

Todas as ditaduras ou golpes em nossa história buscam proteger e consolidar a associação dos interesses internos e externos do capital. Por isto se coadunam, em especial a partir da ditadura empresarial militar, com a ativa participação do imperialismo norte-americano. 0 documentário de Camilo Tavares, Um dia que durou 21 anos, é emblemático por mostrar em detalhe e em documentos-fonte esses traumas. No atual golpe, as tramas se efetivaram e se efetivam à luz do dia.

O argumento explícito do atual golpe, como em 1964, incide sobre motivações morais, tendo agora como centro a corrupção. A montagem da Operação Lava Jato, instalada em 2014, logo após a reeleição de Dilma Rousseff, nada tem de inocente, e une interesses internos, para consumar o golpe, e externos.

Os externos materializam-se pelo "olho grande" do império norte-americano nas fontes energéticas, sobretudo a quebra do monopólio da Petrobras e a insatisfação com a política externa brasileira, mormente sua liderança na América Latina e a formação do grupo político de cooperação, formado por Brasil, Rússia, Índia, China e África do Sul (Brics). Mas também o "olho" na vastidão de terras e na riqueza do subsolo em minerais valiosos, agora em aberta entrega ao capital estrangeiro.

Outro componente que se repete neste golpe, de forma avassaladora, é o papel da mídia empresarial, verdadeira máquina de moer cérebros na produção da desqualificação dos governos Luiz Inácio Lula da Silva e Dilma Rousseff, quer mediante o fetiche das pedaladas, quer pelas 
simples sinalizações de indícios de delações de criminosos confessos transformados em "verdades insofismáveis". Os cânones do credo do direito positivo permitem, quando necessário, cometer a justeza da injustiça, fazendo da versão do fato o critério de verdade daquilo que se quer provar.

A delação premiada, como mostra Giorgio Agamben (2015), é um dispositivo religioso incorporado no direito positivo. A mistura de preceitos religiosos com religião, sublinha Agamben, conduz ao paroxismo. O aspecto contraditório, que engendra positividade, todavia, anota Agamben, é que depois de iniciada a delação nenhum governante estará livre da possibilidade de ser incriminado.

Esta, sem dúvida, é mais uma artimanha do direito positivo que, em sua essência, é o direito da classe dominante. No caso atual, esta artimanha está se mostrando, com algumas contradições, um instrumento para incriminar políticos que possam alterar a direção dos objetivos da classe dominante com o golpe. A prisão de alguns executivos de grandes empresas e a criminalização seletiva de alguns políticos não elidem, na guerra de grupos por poder, que aproximadamente $80 \%$ das condenações à prisão se deem em função de delitos, na maioria de pequenos contra o patrimônio privado.

Outro componente que se repete, mas com elementos novos, é a leniência do Poder Judiciário. Um poder preponderantemente a serviço da classe dominante. Mas no atual golpe, com setores claramente mais ativos, o que permitiu à classe dominante brasileira promover 0 golpe sem apelar para as forças armadas, dando-lhe a formalidade do rito jurídico "democrático". O que se acresce no atual movimento é a clara judicialização da política e a politização do Poder Judiciário. Também historicamente, de forma efetiva da classe dominante, pelo simples fato de que este é guardião do direito positivo e não da Justiça.

No plano político, o golpe de Estado radicaliza-se, pois, com traços fascistas. Instaura-se na sociedade e na Educação o estado policial. Um estado em que, como mostram Giorgio Agamben (2015) e Antônio Cândido (1972), a polícia ocupa o lugar do estado de direito, criminalizando antes, para justificar em seguida; a condenação sem obedecer ao estado de direito. A delação premiada, neste contexto, e o inquérito têm a função de extrair do criminalizado a verdade que interessa ao poder.

Antônio Cândido sintetiza a estratégia do processo que, para arrancar a verdade que interessa, conduz, se necessário for, o criminalizado ao aniquilamento do seu eu. 
De fato, a polícia tem necessidade de construir a verdade do outro para poder manipular o eu do seu paciente. A sua força consiste em opor o outro ao eu, até que este seja absorvido por aquele e, deste modo, esteja pronto para o que se espera dele: colaboração, submissão, omissão, silêncio. A polícia esculpe o outro por meio do interrogatório, o vasculhamento do passado, a exposição da fraqueza, a violência física e moral. No fim, se for preciso, poderá inclusive empregar a seu serviço este outro, que é um novo eu, manipulado pela dosagem de um ingrediente da mais alta eficácia: o medo - em todos os seus graus e modalidades. (CÂNDIDO, 1972, p. 3).

Sob o título Polícia soberana, Agamben mostra a mudança dos princípios do estado de direito em relação ao inimigo a partir do final da Primeira Guerra Mundial. Mudança que assume maior ênfase na Guerra do Golfo e, mais recentemente, contra o terrorismo. Referindo-se a esta mudança após a Primeira Guerra Mundial, Agamben destaca:

[...] o inimigo vinha antes excluído da humanidade civil e carimbado como criminoso; apenas posteriormente torna-se lícito aniquilá-lo com uma "operação de polícia" que não é obrigada a respeitar nenhuma regra jurídica e pode, portanto, confundir, com um retorno às condições mais arcaicas da beligerância, população civil e soldados, povo e seu soberano-criminoso. (AGAMBEN, 2015, it. p. 100).

Note-se que o ódio ao imigrante desenvolveu-se na Alemanha bem antes do Estado nazista. Este é o resultado e não início de um processo. Por certo, este é o recado que Luiz Fernando Verissimo nos dá na crônica O alarme, escrita no contexto dos sinais presentes nas manifestações de rua, a partir de 2014.

\begin{abstract}
Haveria um momento na vida das pessoas ou das sociedades em que funcionaria um alarme parecido com o que alertou o Universo para a chegada dos temíveis humanos, no filme. Pode-se especular sobre qual seria esse momento para um judeu na Alemanha, nas primeiras manifestações do nazismo, por exemplo. Seria a pregação racista do partido mesmo antes de assumir o poder? Seria o que já se sabia do pensamento de Hitler e outros teóricos do fascismo? Qual o exato instante em que este hipotético judeu se convenceu que era preciso fugir do holocausto que se aproximava? Para muitos o aviso nunca veio, ou veio tarde. Muitos não acreditaram que o nazismo chegaria ao poder e depois aos seus excessos. E pagaram por não reconhecer o momento. Demorou algum tempo para que o resto do mundo se desse conta do que estava acontecendo na Alemanha nazista. (VERISSIMO, 2014, p. 1).
\end{abstract}

Duas palavras que se constituem em signos que necessitam de cuidados na análise, pois se firmam na lógica da criminalização e na eliminação do outro: mortadela e petralhas. A primeira é de condenação e ódio aos pobres por terem sido incorporados, ainda que, precariamente, ao consumo, e por políticas de inclusão nas universidades, institutos federais. A segunda, combinação de PT com a figura dos Irmãos Metralhas (quadrilha de ladrões nos desenhos animados), é a expressão do ódio não somente ao Partido dos Trabalhadores (PT), mas ao pensamento crítico.

Em síntese, o ardil novo do atual golpe de Estado é que, ao mesmo tempo que se dissimula mediante o rito parlamentar e a legalidade jurídica, esconde-se o caráter de violência 
que assume a forma capital para enfrentar as contradições insanáveis de sua crise estrutural. Isto num contexto diverso da ditadura empresarial militar.2

Com a apropriação privada de mais um salto tecnológico e a derrocada do socialismo realmente existente, o capital já não pede apenas ajustes, mas austeridade3. Palavra que vem dos países do capitalismo central e que na periferia tem efeito mais radical, como explicitam as contrarreformas acima mencionadas. Aqui se materializa uma das faces do estado de exceção, que não é nova, mas que, dentro do golpe, assume um caráter explosivo: a autonomia do Banco Central para assegurar os interesses e ganhos do capital. A palavra que afirma esta autonomia é blindagem do econômico da política. Isto significa que a real política é a dos interesses do capital.

A outra face do estado de exceção é a sua crescente marca policial. Um traço que, como observam Cândido e Agamben, tem de específico a não obediência ao estado de direito e de operar criminalizando antes para, em seguida, condenar. Cumpre, da mesma forma, a disseminação da pedagogia do medo como antídoto à organização e à luta política.

\section{Quais os desafios e tarefas que nos são demandados para alterar as circunstâncias no plano do conhecimento e da restauração do estado de direito?}

O que assinalamos até aqui nos mostra que os desafios e as tarefas que nos aguardam são enormes, mas a história e o método materialista histórico dialético de compreendê-los nos dão elementos para entender que as circunstâncias postas podem ser modificadas pela unidade diversa, mas indissociável do pensar crítico e da ação política revolucionária. Unidade que, de imediato, as ditaduras e os golpes protagonizados pelos detentores do capital buscam combater com as armas letais ou com as armas do arbítrio da lei.

Isto nos indica que a primeira tarefa é prosseguir pautando o que tem sido o eixo fundamental da sequência dos simpósios sobre a Produção do Conhecimento: produção do conhecimento crítico na tarefa de desvelar o que subjaz às visões cientificistas e pós-modernas e na afirmação da ação política prática na busca da superação das relações sociais capitalistas. Como de forma insistente, nos lembra José Barata-Moura que, em Marx, o que transforma é a mudança material na qual a ciência histórica tem um papel revolucionário.

\footnotetext{
${ }^{2}$ Para entender as estratégias da classe dominante brasileira na construção dos golpes e ditaduras, para manutenção de seus interesses e privilégios, ver texto de Roberto Amaral: Lembremos 1961. Disponível em: contato@ramaral.org. Acesso em 28 jul. 2017.

3 Para uma compreensão da natureza estrutural e agressiva contra os direitos da classe trabalhadora, ver Mészáros (2002) e Harvey (2016).
} 
Para finalizar, certamente reiterando alguns aspectos de colegas que me antecederam, vou brevemente desvelar o ponto central relacionado à produção e à socialização do conhecimento que engendra a contrarreforma do Ensino Médio e sua elevação ao paroxismo pelos ideólogos e teólogos fundamentalistas do Movimento Escola sem Partido.

A referência das concepções de conhecimento sobre as quais repousam a contrarreforma e o foco real dos partidários do movimento Escola sem Partido tem sua base social e política nas teses de Friedrich Hayek. Com efeito, no contexto da derrota do socialismo real (não o fracasso), Margaret Thatcher, por 11 anos primeira-ministra da Inglaterra, proclamou que não via a sociedade, mas sim indivíduos, e deu espaço às teses produzidas por Friedrich Hayek na década de 1940 em seu eu clássico livro O caminho da servidão (1987).4 Nele, a tese central é que as políticas sociais e socialistas levam à servidão e, o livre mercado, à liberdade e à prosperidade. Tese compartilhada pelos componentes da organização internacional fundada em 1947 em conferência protagonizada por Hayek e partilhada por Milton Friedman, Karl Popper, entre outros, em Mont Pèlerin, França. Conhecida como Sociedade Mont Pèlerin, constitui-se na base teórica e política do que se denominou neoliberalismo. Trata-se, no plano do conhecimento, do retorno ao liberalismo conservador de cunho empiricista e, no plano político, às teses da soberania do livre mercado.

O retorno às teses ultraconservadoras da soberania do mercado dá atualidade a análise de Marx no trabalho 018 de Brumário de Luís Bonaparte, quando afirmou: A história se repete a primeira vez, como tragédia e, a segunda, como farsa. Com feito, a doutrina neoliberal, como analisa Perry Anderson (1995), teve início prático na ditadura Pinochet, no Chile, mas aos poucos expandiu-e para o mundo. No Brasil, ela se tornou programa efetivo no governo de

\footnotetext{
4 Outras obras deste mesmo autor enfatizam a soberania do mercado como: Liberdade de escolher (1987) e Direito, legislação e liberdade: uma nova formulação dos princípios liberais de justiça e economia política (1985). Note-se que foi a partir das análises do grupo da Sociedade de Mont Pèlerin que, tecnocratas e economistas do sistema capital, liderados pelos Estados Unidos e com a participação de representantes de organismos econômicos internacionais e de economistas de países da América Latina elaboram a cartilha neoliberal conhecida como Consenso de Washington. Tal consenso foi produzido para submeter às economias latino-americanas a um conjunto de regras as quais garantiriam os investimentos do capital, mormente o financeiro. São elas: disciplina fiscal - o Estado deve limitar os gastos à arrecadação, eliminando o déficit público; redução dos gastos públicos; reforma fiscal e tributária, na qual o governo deveria reformular seus sistemas de arrecadação de impostos e ampliar a base sobre a qual incide a carga tributária, com maior peso nos impostos indiretos; abertura comercial e econômica dos países, a fim de reduzir o protecionismo e proporcionar um maior investimento estrangeiro; taxa de câmbio de mercado competitivo; liberalização do comércio exterior; investimento estrangeiro direto, eliminando as restrições; privatização, com a venda das estatais; desregulamentação, com o afrouxamento das leis de controle do processo econômico e das relações trabalhistas; direito à propriedade intelectual. Disponível em: (https://www.estudopratico.com.br/consenso-de-washington-objetivos-regras-e-o-brasil/. Acesso em 25 jul. 2017.
} 
Fernando Enrique Cardoso em que, não por acaso, como mencionamos acima, o núcleo intelectual articulador do golpe e fiador das contrarreformas é daquele período. No campo da Educação no Brasil, é quando se assume as teses dos organismos econômicos internacionais, guardiães do mercado e do capital, e dos institutos privados do mundo empresarial.

Os pontos centrais defendidos na década de 1990 eram, entre outros, os seguintes:

A escola pública era ruim porque era mal gerida. O que a melhoraria seria a adoção da eficiência e efetividade da gestão privada; no plano dos conteúdos, a escola pública básica ensinava coisas demais e desnecessárias, e, além disto, aqueles que têm necessidade (destinados) de entrar precocemente no mercado de trabalho não precisam aprender tudo. Para tanto, impuseram o Decreto no $2.208 / 1997$, formalizando em Lei a dualidade estrutural da educação.

A escola pública não respondia às demandas do tempo presente porque a formação docente era impregnada de teorias sociais, culturais, econômicas e políticas desnecessárias. 0 que caberia aos cursos de formação era ensinar aos futuros docentes as "regras do bem ensinar". Tratava-se de formar entregadores do conhecimento, produzido por institutos privados ou por parcerias público-privadas.

Estas teses foram sendo pautadas, ao longo dos 15 anos do governo brasileiro, pelo bloco de coligações articuladas pelo Partido dos Trabalhadores, pelo Movimento Todos pela Educação. Sobre este aspecto, o pensamento educacional crítico produziu análises que orientaram a luta política. O que não nos damos conta é que o ovo da serpente estava sendo gestado no Movimento Escola sem Partido.

A Escola "sem" Partido, como a denominei, numa coletânea que organizei, de esfinge que ameaça a educação e a sociedade brasileira (FRIGOTTO, 2017), engendra o ovo de serpente que conjuga o fascismo de mercado, o fascismo político e midiático com a leniência da maioria do Poder Judiciário.

O que cabe enfatizar é que, na verdade, o que denominam ideologização, doutrinação, lavagem cerebral têm por traz a defesa da neutralidade do conhecimento de do processo educativo. Isto fica evidente quando se tira a máscara moralista e se vai ao que de fato um dos seus fundadores, Miguel Nagib, árduo defensor do movimento escola sem partido, expõe em depoimentos ao definir o papel do professor, da escola e do aluno: "Professor deve ensinar o que está prescrito. Ele é um burocrata do estado. Pode ensinar, mas não educa; a escola deve 
atender aos consumidores e como tal deve ser regida pelo Código do Consumidor; o aluno é propriedade dos pais."

A postulação de transformar o Movimento Escola sem Partido em lei significa legalizar, como verdade suprema, o partido único do mercado e do capital. A convocatória no site para que pais, alunos e colegas denunciem os professores que não seguem sua cartilha traduz a pedagogia do medo e da eliminação daqueles que têm uma análise divergente. Unem-se, nessa tarefa, o fundamentalismo econômico, político, religioso e midiático.

A reversão das circunstâncias criadas pelo golpe de Estado situa-se no plano da luta política e no plano macro e micro da sociedade e da educação. Afirma que não tem um antes ou um depois, mas uma luta concomitante contra o projeto golpista no todo e no detalhe.

Considerando a natureza do atual golpe e a dispersão das forças políticas da esquerda, somente a sua unidade, em seu pluralismo, e a inclusão de outros setores democráticos poderão barrar a continuidade e os efeitos do golpe sobre a classe trabalhadora.

Neste sentido, entendemos que em termos macropolíticos as seis ou sete dezenas de organizações políticas, movimentos sociais e populares do campo e da cidade que compõem a Frente Brasil Popular apontam o sentido e a unidade para tarefas de resistência a curto prazo e tarefas a médio e longo prazos.

No curto prazo, as tarefas detalhadas no Plano Popular de Emergência destacam:

A saída democrática que propomos tem como pressuposto a antecipação das eleições presidenciais para 2017. Esse é primeiro passo para se travar uma ampla e persistente disputa política capaz de criar uma correlação de forças favorável à oportuna convocação de Assembleia Nacional Constituinte, destinada a refundar o Estado de direito e estabelecer reformas estruturais democráticas ${ }^{5}$.

A condição imediata é, pois, lutar pela saída do "golpista" Michel Temer e pela convocação das eleições direitas antecipadas. No médio prazo, a luta é para instaurar uma Assembleia Nacional Constituinte, a fim de estabelecer as reformas estruturais de que o país necessita e que foram até o momento postergadas.

Trata-se de implementar um projeto nacional de desenvolvimento que vise a fortalecer a economia nacional, o desenvolvimento autônomo e soberano, enfrentar a desigualdade de renda, de fortuna e de patrimônio como veios fundamentais para a reconstrução da economia brasileira, para a recomposição do mercado interno de massas, da indústria nacional, da saúde financeira do Estado e da soberania nacional, um modelo social baseado no bem-estar e na democracia. ${ }^{6}$

5 Frente Brasil Popular. Plano Popular de Emergência. Disponível em: http://frentebrasilpopular.org.br/system/uploads/action_file_version/b9769c87753c384b277f1f828ac7721d/file/pp e.pdf. Acesso em 24 jul. 2017.

${ }^{6}$ Frente Brasil Popular. Plano Popular de Emergência. Disponível em: 
No plano específico da universidade e centro de pesquisa, cabe resistir à batalha das ideias e desmontar a ideia de que a única alternativa à crise não são a superexploração e a espoliação dos trabalhadores. Mas mostrar, por outro lado, que se a corrupção deve ser combatida, ela é da essência do capitalismo, e destacar que a maior corrupção não é da propina, e sim a sonegação de impostos pelas grandes corporações econômicas e o pagamento de juros ao capital financeiro mediante a dívida pública.

No campo específico da crise da Educação e da Saúde, nosso desafio é mostrar que esta não é uma causa que interessa apenas aos trabalhadores do setor público, mas ao conjunto da classe trabalhadora, em particular, os setores mais pobres.

Um horizonte imediato de retomada das lutas coletivas em defesa da educação pública universal, gratuita, laica e as concepções da escola unitária, formação politécnica/tecnológica e do Ensino Médio integrado é somar-se na organização em curso da Conferência Nacional Popular de Educação. Mas também cabe a luta permanente em nossas organizações científicas e no cotidiano de nossas instituições.

Trata-se de não ceder à pedagogia do medo, mas de "Murar o Medo" como nos convida o escritor moçambicano Mia Couto ao analisar as estratégias do capital para manter seus processos de dominação. Couto conclui citando Eduardo Galeano, que nos fala do medo global.

\footnotetext{
Os que trabalham têm medo de perder o trabalho; os que não trabalham têm medo de nunca encontrar trabalho; quando não têm medo da fome têm medo da comida; os civis têm medo dos militares; os militares têm medo da falta de armas e as armas têm medo da falta de guerras. "E, se calhar, acrescento agora eu: há quem tenha medo que o medo acabe",
}

A forma de não ceder ao medo é a organização coletiva e solidária da luta pela reconquista do estado de direito e pela revogação de todas as contrarreformas. Uma luta que não é apenas política, mas ética, pois se o golpe prosseguir não haverá futuro minimamente previsível no que é elementar à vida para a maioria da classe trabalhadora.

http://frentebrasilpopular.org.br/system/uploads/action_file_version/b9769c87753c384b277f1f828ac7721d/file/pp e.pdf. Acesso em 24 jul. 2017.

${ }^{7}$ Disponível em: https://papodehomem.com.br. Acesso em 24 jul. 2017. 


\section{REFERÊNCIAS}

AGAMBEN, Giorgio (2015). Maios sem fim. Notas sobre a política. Belo Horizonte; São Paulo: Autêntica.

ANDERSON, Perry (1995). Balanço do neoliberalismo. In: EMIR, Sader; GENTILI, Pablo Gentil (Orgs.). Pós-neoliberalismo: as políticas sociais e o estado democrático. 4. ed. Rio de Janeiro: Paz e Terra.

BOSI, Alfredo (2010). Dialética da colonização. 4. ed. São Paulo: Companhia das Letras.

CÂNDIDO, Antônio. O caráter da repressão. Jornal Opinião, 1972. Disponível em: outraspalavras.net/Brasil. Acesso em 29 jan. 2017.

FERNANDES, Florestan (1973). Capitalismo dependente e classes sociais na América Latina. Rio de Janeiro: Zahar.

A revolução burguesa no Brasil: ensaio de interpretação sociológica. Rio de Janeiro: Zahar, 1974.

FRIGOTTO, Gaudêncio (2017). Escola "sem" partido: esfinge que ameaça a educação e a sociedade brasileira. Rio de Janeiro: Edições LPP/ Uerj.

HAYEK, Friedrich (1985). Direito, legislação e liberdade: uma nova formulação dos princípios liberais de justiça e economia política. São Paulo: Visão.

. O caminho da servidão. Rio de Janeiro: Instituto Liberal, 1987. . Liberdade de escolher. Rio de Janeiro: Record, 1980.

HARVEY, David (2016). 17 contradições e o fim do capitalismo. São Paulo: Boitempo.

MARX, Karl (2003). Crítica da crítica absoluta ou a crítica, conforme o Senhor Bruno. In: MARX, Karl; ENGELS, Friedrich. A sagrada família. São Paulo: Boitempo.

MÉSZÁROS, Istvan (2002). Para além do capital: uma teoria da transição. São Paulo: Boitempo.

MOTTA, Vânia Cardoso; FRIGOTTO, Gaudêncio (2017). Por que a urgência da reforma do Ensino Médio. Revista Educação e Sociedade. Campinas - SP, n. 38. p. 355-72.

RAMOS, Marise Nogueira; FRIGOTTO, Gaudêncio (2017). Medida Provisória no 746/2017: a contrarreforma do ensino médio do golpe de estado de 31 de agosto de 2016. Revista Brasileira de História da Educação (RBHE).

VERISSIMO, Luiz Fernando (2014). O alarme. Jornal O Globo, 21 de fevereiro de 2014. Disponível em: http://jornalggn.com.br/noticia/luis-fernando-verissimo-o-alarme. Retirado em 25 jul. 2017.

. Ódio. Jornal O Globo. Caderno Opinião. Rio de Janeiro, 25 de junho de 2015.

Disponível em: http://oglobo.globo.com/opiniao/odio-16546533\#ixzz3eAZnOCwa/. Acesso em 20 abr. 2017. 